\title{
Study on Safety Management of College Students based on Behavior Based Safety Guo-Tong QIAO ${ }^{1, a}$, Hong ZHANG ${ }^{2, b}$ \\ ${ }^{1,2}$ Anhui University of Science \& Technology Huainan, 232001, China \\ agtqiao@126.com, ${ }^{\mathrm{b}} \mathrm{coke2093@163.com}$
}

Key Words: University student management, Behavior Based Safety(BBS), Behavior analysis.

\begin{abstract}
The health and safety condition of college students, who play a crucial role in future social construction, are widely gaining attention. The college students are confronted with many problems because of mismanagement. Based on behavior observation and meticulous analysis, BBS focuses on unsafe behavior of students, and then guides students to foster their healthy and safe habit through positive stimulus constantly. This paper strives to provide a new college student management viewpoint by establishing safe management system of colleges based on BBS.
\end{abstract}

\section{Introduction}

By the end of 2012, the number of college students in our country has reached 2,535,600. What's more, the number of higher school graduates reached a historical number at 68 million. The number of college students has hit a new record in 2013, though less students attended the university entrance examination. Such a large group of college students is an important part of the main force of human resources in our country, the health and safety of students not only concerns the quantity and quality of human resources directly, but also is directly related to the strategy of reinvigorating China. On account of the influence of students' family, regional and educational environment, the management of college students' health and safety is doomed to be complex and difficult. Studies have shown that college students with physiological or psychological diseases reach $45.4 \%$ [1], and negative social news or unsafe behavior caused by college students is nothing new now. Deepening of China's economic and social reform has brought students management theory and methods profound impacts as well as challenges and problems. Many experts have made analysis and explorations about the condition of college students' health and safety[2-4]. This paper researches unsafe behaviors of university students from the perspective of behavior safety management, find defects that exist in safety management system, thus improve the quality of college students' health and safety effectively.

\section{The Status of College Students' Health And Safety}

\section{The Status of Health}

According to the existing documents and surveys analysis, the condition of college students' health and safety has not been radically improved. As a result the development of colleges and universities is hampered someway. These problems mainly reflected in:

Bad Habits. A research on college students' health and life behavior shows that $65.68 \%$ of them "have a feeling of lack of exercise", $7.57 \%$ don't eat breakfast, $15.44 \%$ have no idea of the importance of balanced diet. Nearly $1 / 3$ smoke and more than a half drink. Many students live a life without rule, for example, the phenomenon of playing games all night is serious, which will cause dizziness tinnitus or inattention in short-term and form cervical vertebra disease, lumbar disc and so on in long-term .

Shortage of Physical Exercise. According to the recent National Physique Monitoring Bulletin, the explosive force, strength and endurance of students continue to decline. The way to relax for students is seldom. Only $19.12 \%$ students often participate in sports, while more than $50 \%$ choose static methods, such as network games or chess games, to kill time, which 
resulted in $13.6 \%$ students are suffering obsession of overweight or obesity.

Poor Psychological Health. The pressure of college students' employment keeps increasing in recent years, and many schools always focus on the employment rate and pay less attention to mental health and social adaptation ability of college students. A large network survey launched by College Journal and college students shows that $27 \%$ students often suffer from psychological problems, including interpersonal communication, employment and emotional confusion.

\section{Security Situation}

Poor Safety Awareness. Students often sink into disarray once emergencies happen because of safety knowledge lacking. They use high-power electrical appliances, smoke in the dormitory and violate the rules on purpose crossing the street. A survey produced by the author shows that a majority of students don't know how to use fire fighting equipment, and more than $70 \%$ have never received systematic training about emergency respond and self-help.

Complicated Security Environment. University campuses are mostly open, so social idles are easily to enter. The increasing of valuables around the students provides an opportunity for the lawless to hurt life or property safety. In addition, that some students are addicted to the network and browse adverse information can bring them online fraud.

The health and safety state of college students is not optimistic, which directly leads to the evolution of unsafe behavior of college students, and becomes the difficulties of college student management.

\section{Safety Management and Operating Mechanism}

Behavior Based Safety (BBS), established on the basis of psychology, management and organizational behavior, choose the "unsafe acts" as the object of study, gradually correct the unsafe behavior by key behavior recognition, and finally reduce or eliminate the safety problem.

An important part of the BBS is to carry out an Activation-Behavior-Consequence (ABC) analysis on dangerous behaviors, which means that human behavior will be divided into chain mode including antecedent, behavior, and consequence. Generally, it's considered that "antecedent" cause "consequence", and due to the stimulation of the antecedent, it will show what people see is metaphysical. For example, many girls believe they are overweight and also feel sports are time-consuming, so they believe it's better to take medicine whose effect is more obvious. However, it is reasonable just on surface. In fact, such opinion ignores the subjective initiative of human, and the idea is resulted essentially from incorrect cognition of antecedents which stimulate the event. People often have different attitudes towards the same thing, and act differently, resulting in different results. BBS, working on the "causes" "results", can change people's behavior pattern, and ensure the desired results continue to occur.

Study on the behavior of safety management starts earlier abroad and widely applied in petroleum and chemical industry etc. Studies show that spending $2 \%$ of their time to develop safety behavior model can obtain $10 \%$ of the safety improvement [5]. After the implementation of the model, the safety awareness of employee gets promoted, and they will work with full self-consciousness, self-control which will eliminate potential safety problems. There are many successful cases: the USA DuPont COSTOP tools, the German AHA [6]. In recent years, as "people-oriented" concept deepening, BBS theory began to get attention in our country and has been applied to enterprises or government agencies constantly. This paper is to explore the solution for college students' health and safety management.

\section{Security Management Model}

\section{BBS Main Working Mechanism (Fig. 1)}

Preparation. In this section we need to establish the BBS leadership team and receive training, complete the safety behavior assessment of the students, and then set primary stage expected improvement goals. 
Definition of Critical Behavior. Collect safety accidents of college students through various ways, analyze the unsafe behavior and confirm the key behaviors, so as to make safety observation table.

Behavior Observation. Behavior observers regularly or irregularly use safety table to conduct observation, find unsafe behaviors and report to the BBS leadership team in time.

Behavior Intervention. This is a process to re-stimulate the unsafe behavior of students. First, develop effective intervention strategies. By this new stimulation of correcting unsafe acts, students can consciously avoiding unsafe behaviors. Note that this stimulus should focus on encouraging the safe behavior patterns, otherwise students easily think that changes costs too much to keep [7-8].

Effect Evaluation. This process must apply mutatis mutandis to the previous observations, analyze whether the unsafe behavior has been corrected or improvement objectives have achieved effectiveness. And then identify weaknesses and define a new round of key behaviors.

\section{BBS Implementation Processes in the Management of College Students}

Preparatory Stage. Set leading group consists of Students Affairs Office, Academic Administration and psychology counseling center and student advisor. Attendance of leaders from Academic Administration and Students Affairs Office helps the specific work of the overall implementation, the departments' responsible person can help to grasp the actual situation of the students and formulate specific rules, and psychological counseling teacher can offer professional advices. The leading group is mainly responsible for data analysis, the supervision of progress towards the goals and makes plans for the next action [9].

Second, they must receive formal training to understand the basic processes of BBS and ABC analysis, and learn to analyze students' behavior. Then organize the collected information into a summary table to observe unsafe behavior, explore the most important factors affecting the health and safety conditions, define critical action and develop effective improvement goals.

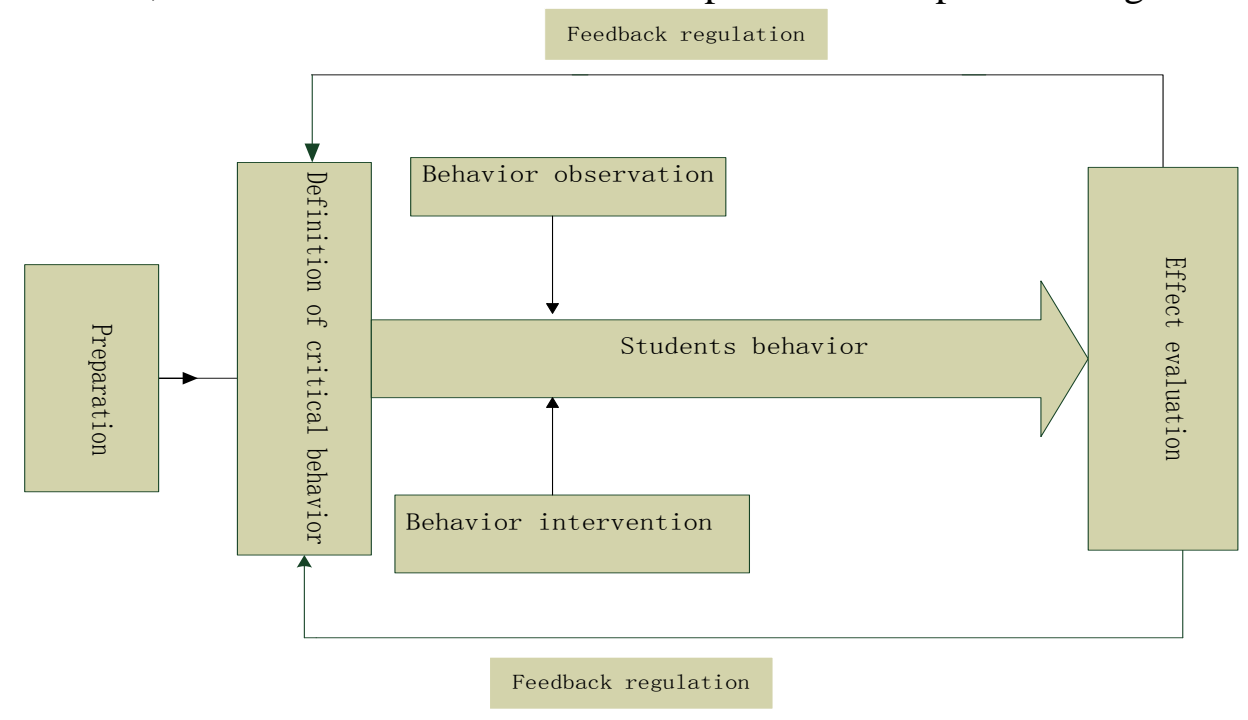

Fig.1 BBS main mechanism

Process of Behavior Observation. In the enterprise or project, the observation period of BBS maps directly to operation, and workflow often have a set of norms, so that observers have a set of standard which they can refer to. However, these differs from students' health and safety management, the campus environment does not allow the observer to observe the students' every act or move, so this stage will have certain difficulty, need to cooperate with teachers and students. It is necessary for BBS leadership group to take effective measures to collect information, such as issuing anonymous questionnaire survey in the network. Schools with better conditions can use stratified sampling method to select representatives to hold a forum. Then the student cadre or designated person worked as observer, and enter the students' lives to produce the observation process. Observation is not equal to monitoring, but just submits the data of health and safety issues 
in tabular form. In the process of collection, pay much attention to controllability, measurability and reliability.

Process of Behavior Feedback. By analyze the raw observation data from $A B C$ and feedback the results of the analysis, the relevant personnel can provide safety guidance and block the appearance of unsafe behavior by repeated stimulation which can make safety behavior to become a habit. Announce the observation results in time is the antecedents of early warning, and through the positive incentives or rewards, such as supplemented by recognition, so as to maintain the enthusiasm of students to participate and solidify the safety behavior. BBS feedback cycle can be timely adjusted according to the term length, and eventually formed a good atmosphere of security. The ideal outcome is to complete the intergenerational inheritance and build a safety culture so that the new can fit in naturally, thus forming a virtuous circle. Note that, the key part of previously defined behavior will gradually disappear over time, it will needs to be reevaluated and define new key behavior until the unsafe behavior reduced to an ideal level.

\section{Other protection mechanisms}

There are many successful examples of BBS in business management, but in practice, the situation of safety management for college students is less, Search key words such as "Conduct Security Management" and "College Safety Management" in the "Chinese knowledge net "," Articles knowledge service Platform ", after removing articles of low correlation, we doesn't find similar literature. In addition, because of our limit understanding of BBS, when applied to college, BBS Management has some shortcomings, which need to be supplemented protection mechanism.

\section{Universal Participation}

One important feature of BBS in the management is emphasized the participation of basic level staff. Without their participation and understanding, the formulated regulations are often treated as attempting an ineffective solution[10]. At the same time, all work can not be put into the sufficient manpower smoothly without the understanding and support from the management layer, which is also one of the reasons why the school leadership must participate in the BBS leadership team. Finally, we should gain direction and cooperation from relevant experts, then can find problems easier in the behavior observation results.

\section{Pay Attention to the Process of Efficiency}

The BBS can learn from the advanced experience at home or abroad, but we should avoid Ism resolutely. It is necessary for us to learn from the process design of enterprise and take the special nature of management object into account. We should develop critical behavior which is in line with school, for example, different living behavior characteristics, laws and campus security determine different critical behavior. Finally, each link is mutually matched, we should try hard to avoid conflict situation.

\section{Combined with the Existing Management System}

BBS is a useful complement to strengthen school health and safety management, but it is not self-contained [11], it still need to be integrated with the existing management system integration to achieve maximum function. For example, combined with early warning mechanism, academic and university psychological crisis investigation mechanism, it will be easier to improve behavior management effect. At the same time, it must be clear that the BBS should be effectively brought into the existing allocation of responsibilities and rights, which should be fully discussed with the investigation to avoid management vacuum.

\section{Continue to Improve BBS System}

In the run-in with the existing management system, it will inevitably leads to friction. In addition, because of experience lacking, the new use of the BBS system may cost a period of time to explore, we need to debug it constantly and train the leading group timely, improve the behavior observation system and incentive mechanism, through continuous positive incentive means to improve health and safety behavior. 


\section{Conclusion}

Poor health and safety status of college students has lead to many malpractices, such as low student physical quality and psychological quality. The existing management measures mainly emphasize punishing and pay too much attention to the consequences of behavior, but lack of proper guidance. In addition, the management of "people-oriented" spirit is not in place, which can not reflect the students' initiative and sense of ownership.

Behavior safety management is used mainly for petrochemical industry and other industrial enterprises management in practice. It also has a good performance in the general business or agency recently. This paper applied BBS to the management of college students, focuses on students' unsafe behavior, establish a safety management system to explore the operation mechanism. By observing students' behavior, we can determine the key behavior, and carry on the intervention feedback through various forms and ultimately to improve the health and safety status of students. Due to space limitations, we do not discuss the possible conflicts in combination of BBS and the existing management system in detail; this can be our research direction.

\section{Acknowledgement}

This research was financially supported by Higher education revitalization project of the research on teaching reform in Anhui province 2013: Talent training quality evaluation system of "industry-university-institute" cooperation and applied research (2013zdjy079).

\section{Reference}

[1] Guo Shubang. College students' health condition and health related behaviors of [D]. Shandong University, 2011.

[2] Huang Yushan, Chen Baoling, et al. Research on College Students' health condition and life behavior Chinese [J] Journal of physical education,2008.05:72-76.

[3] Liu Qiangui. Problems and Countermeasures [J]. Journal of Inner Mongolia Normal University of safety management work of College Students under the new situation (PHILOSOPHY AND SOCIAL SCIENCE EDITION),2012.09:78-82.

[4] Pi Zuxun, Liu Heqing, Zhu Guomei. Effect of College Students' safety factor [J]. Journal off Xiangtan teachers college. (SOCIAL SCIENCE EDITION), 2007.11:27-29.

[5] Xu Weidong. Behavior safety management "eight errors" [J]. modern occupation safety, 2011 (2): 92-95.

[6] Helen Lingard,Steve Rowlinson. Behavior-Based Safety Management in Hong Kong's Construction Industry[M].Journal of Safety Research,1997,28(4): 243-256.

[7] Li Naiwen, season awards. Behavior safety management application in the coal mine in behavior management of [J]. China Safety Science Journal, 2011.12:115-120.

[8] Terry.E. Max temperature. Safety management: the process and implementation of the [M]. Beijing: Publishing House of electronics industry, 2011.08:4955.

[9] Tan Bo, Wu Chao. The 2000 - 2010 safety behavior research and analysis of [J]. Chinese Safety Science Journal, 2011.12:17-26.

[10] Jia Mingtao. Behavior of safety management in the construction of the application of [J]. China of safety science and technology, 2012.07:169-173.

[11] Sun Aijun, Liu Mao. Behavior safety management theory in the practical difficulties and its solution in our country [J] China Safety Science Journal, 2009.09:58-63. 